\title{
Associations between congenital heart defects and genetic and morphological anomalies. The importance of prenatal screening
}

\author{
Jan Pavlicek , Tomas Gruszka a, Sabina Kapralova ${ }^{b}$, Martin Prochazkac, Eva Silhanovad, Romana Kaniovad, Slavka Polanskaa, \\ Renata Cernickovac, Eva Klaskovab
}

\begin{abstract}
Aim. To study congenital heart defects (CHDs), evaluate their relation to extra-cardiac pathologies, and assess the significance of prenatal diagnostics for heart diseases.

Methods. Data from 1999-2017 were analyzed for the incidence of significant CHDs in fetuses (prenatal ultrasound/ echocardiography) and children, including, where applicable, autopsy data and genetic evaluation.

Results. Among 220,400 fetuses, 819 (3.7 cases per 1000) significant CHDs were observed. Of the total, 53\% (435/819) of CHDs were diagnosed prenatally. The heart defect was an isolated impairment in 78\% (640/819), associated with a genetic impairment in 16\% (128/819), and with extra-cardiac malformations without genetic pathology in 6\% (51/819). Chromosomal aberrations were diagnosed prenatally in 70\% (90/128) of those affected and extra-cardiac conditions in $86 \%(44 / 51)$. The CHD and genetic pathology association was more frequent prenatally [21\% (90/435) vs. postnatally: $10 \%(38 / 384 ; P<0.0001)$ ], as was the association between CHD with other extra-cardiac pathology and a normal karyotype [prenatally: $10 \%(44 / 435)$ vs. postnatally: $2 \%(7 / 384 ; P<0.0001)]$.

Conclusion. Heart defects are most frequently isolated, with genetic and other extra-cardiac anomalies in about one third of cases, significantly linked to prenatal diagnostics.
\end{abstract}

Key words: congenital heart defect, screening, fetal echocardiography, genetic abnormality, aneuploidy, extracardiac malformation

Received: January 28, 2018; Accepted: August 22, 2018; Available online: September 6, 2018

https://doi.org/10.5507/bp.2018.049

${ }^{a}$ Department of Pediatrics and Prenatal Cardiology, University Hospital Ostrava, Czech Republic

${ }^{b}$ Department of Pediatrics, University Hospital Olomouc and Faculty of Medicine and Dentistry, Palacky University Olomouc, Czech Republic 'Department of Medical Genetics, University Hospital Olomouc and Faculty of Medicine and Dentistry, Palacky University Olomouc, Czech Republic

${ }^{d}$ Department of Medical Genetics, University Hospital Ostrava, Czech Republic

Corresponding author: Eva Klaskova, e-mail: klaskove@gmail.com

\section{INTRODUCTION}

Heart defects are the most frequently observed morphological defects ${ }^{1}$, representing up to $40 \%$ of all congenital malformations ${ }^{2}$. The incidence of congenital heart defects (CHDs) is typically reported as 6-8 cases per 1000 live births ${ }^{3}$, with ventricular and atrial septal defects as the most common entities. Of the total number of CHDs, $35 \%$ are considered critical. During prenatal development, the heart begins forming by days 18-19 in the cardiogenic zone, arising from the neuroectoderm and the splanchnic part of the mesoderm. Paired endocardial tubes fuse on day 22, followed by compartment formation by rotations and septations, and heart development is completed by pregnancy week 8 . The first contractions of the primitive cardiac tube can be seen by the end of the third week of development. Congenital heart defects may originate in various steps along this pathway, including erroneous rotation of the heart loop, disorders of septation of individual heart compartments and vessels with pathological development of the pulmonary-vascular system, or impaired development of the arterial circulation. Heart defects can be associated with other anatomical anomalies and a secondary presentation of disorders of organs in the thoracic cavity or abdominal cavity.

The etiology of CHDs is complex when genetic and environmental factors also come into play ${ }^{4}$, but typically, multifactorial and unclear influences prevail. Approximately $20-25 \%$ of CHDs are associated with a precise genetic cause ${ }^{5,6}$. The genetics of CHDs has been studied for some time, with a number of clinical trials and recommendations pertaining to the relation between genetic pathologies and CHDs (ref. ${ }^{7}$ ). Newly identified genes and their relevant variants are being studied, together with a possible influence of cryptic chromosomal aberrations $^{8}$. Despite significant progress in genetic diagnostics and knowledge of genetic models and new genes ${ }^{9}$, variable penetrance and phenotype variability are frequently observed, making genetic diagnostics more difficult.

Most significant CHDs can be detected prenatally ${ }^{10}$. In the Czech Republic, screening is performed by a gynecologist, pediatric cardiologist, or a geneticist. If pathology is suggested, the workup will include evaluation of extracardiac anomalies and acquisition of additional genetic examination. The parents are always fully informed and have the option to continue or terminate the pregnancy. 
Prenatal diagnostics for CHDs is improving. The increasing efficacy is associated not only with the development of ultrasound techniques and the better experience of the physicians performing the examination but also with advances in medical genetics.

The aim of the current work was to evaluate the incidence of CHDs to determine their relation to extra-cardiac pathologies and evaluate the significance of prenatal diagnostics in relation to cardiac diseases.

\section{METHODS}

The incidence of CHDs was observed through a 19year retrospective study analyzing data from 1999-2017 for 220,400 fetuses. This population represents the catchment area of the authors' center, i.e., University Hospital Ostrava, a tertiary referral center for pediatric and prenatal cardiology. The incidence of significant CHDs, rate of their prenatal detection, and relation between CHDs and genetic and extra-cardiac pathologies were monitored. A significant heart defect was defined as a surgical procedure performed within the first year of a child's life. In cases of pregnancy termination, an autopsy was performed in the presence of a pediatric cardiologist. Continuing pregnancies were monitored, and newborns with heart defects were delivered at a specialized center. The data were updated continuously, including analyses from genetic reports.

The obtained data were stored and processed using Microsoft Excel. The same program was used for descriptive statistics and chart generation. Results are presented as tables of numbers and percentages. For comparison of categorical variables, the chi-squared test was used. The level of significance $\alpha$ for the probability of a type I error ( $P$ or $P$ value) was set at 0.05 for all tests. The IBM SPSS software v. 24 was used to perform these tests.

\section{RESULTS}

During the 19-year follow-up, a total of 819 (3.7 per 1000 fetuses) CHDs were observed among 220,400 fetuses and newborns. Of these, 53\% (435/819) were detected prenatally. In the study, CHDs were diagnosed at a gestational age between the $12^{\text {th }}$ and $32^{\text {nd }}$ week of pregnancy (median the $21^{\text {st }}$ week). In the prenatal period, only $5 \%$ (22/435) of CHDs were detected in the first trimester. In this group, the defects with a significant change in the morphology of the ventricles and atrioventricular septum (hypoplastic left and right heart, atrioventricular septal defect) prevailed, in $65 \%$ and $35 \%$, respectively. In the first trimester, CHD diagnosis was more associated with extracardiac pathology, $80 \%$ of fetuses had chromosomal aberrations, or another extra-cardiac pathology with a normal karyotype. The overall incidence of CHDs and percent detected prenatally are presented in Fig. 1. The success rate of prenatal detection of significant CHDs increased continuously, from $20 \%$ in 1999 up to the current $80 \%$. In cases of CHDs significantly altering the four-chamber projection of the heart (hypoplasia of the left and right ventricles, common ventricle), the rate of detection reached $100 \%$ in the observed region in recent years. The proportion of successfully detected genetic diagnoses increased with the increasing efficacy of the prenatal screening of CHDs (Fig. 2).

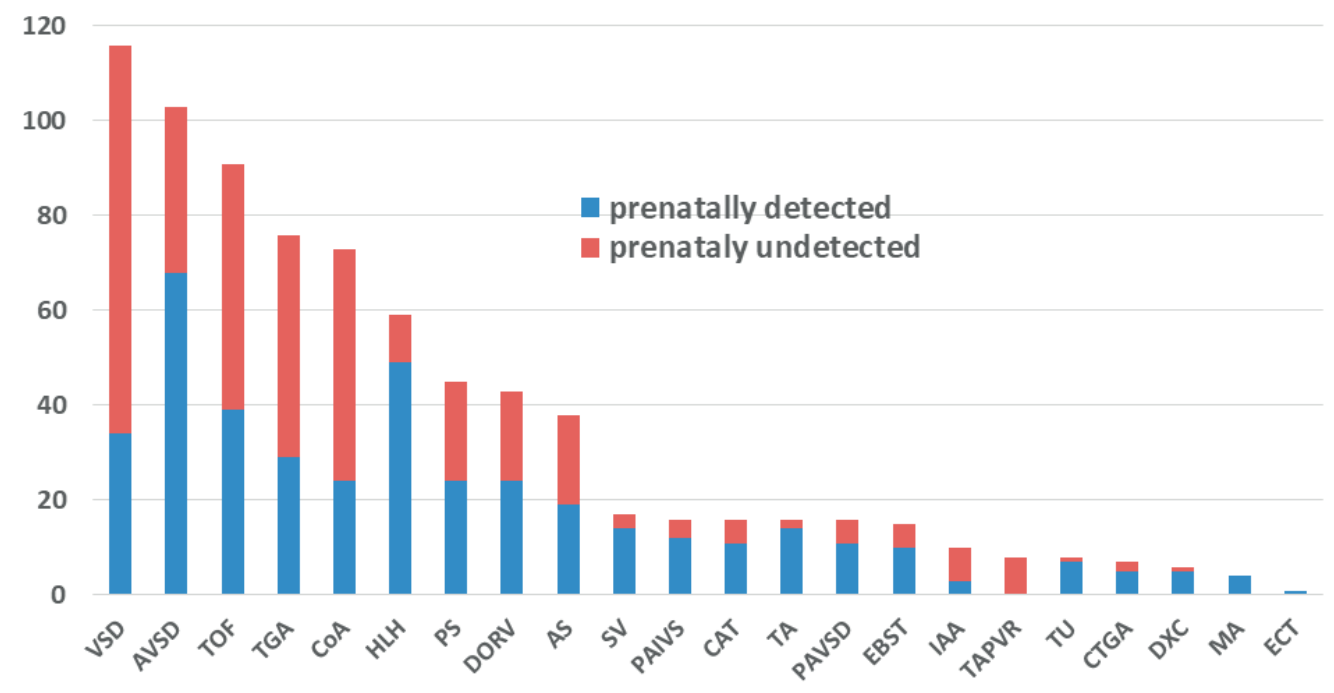

Fig. 1. CHD incidence $(n=819)$ and proportion detected prenatally.

(VSD-ventricular septal defect, AVSD-atrioventricular septal defect, TOF-tetralogy of Fallot, TGA-transposition of great arteries, CoA- coarctation of aorta, HLH-hypoplastic left heart syndrome, PS-pulmonary stenosis, DORV- double outlet right ventricle, AS-aortic stenosis, SV-single ventricle, PAIVS- pulmonary atresia/ intact ventricular septum, CAT- common arterial trunk, TAtricuspid atresia, PAVSD- pulmonary atresia/ventricular septal defect, EBST- Ebstein's anomaly, IAA- interruption of the aortic arch, TAPVR- total anomaly of pulmonary venous return, TU-tumor, CTGA-corrected transposition of great arteries, DXC-dextrocardia, MA-mitral atresia, ECT-ectopia cordis) 


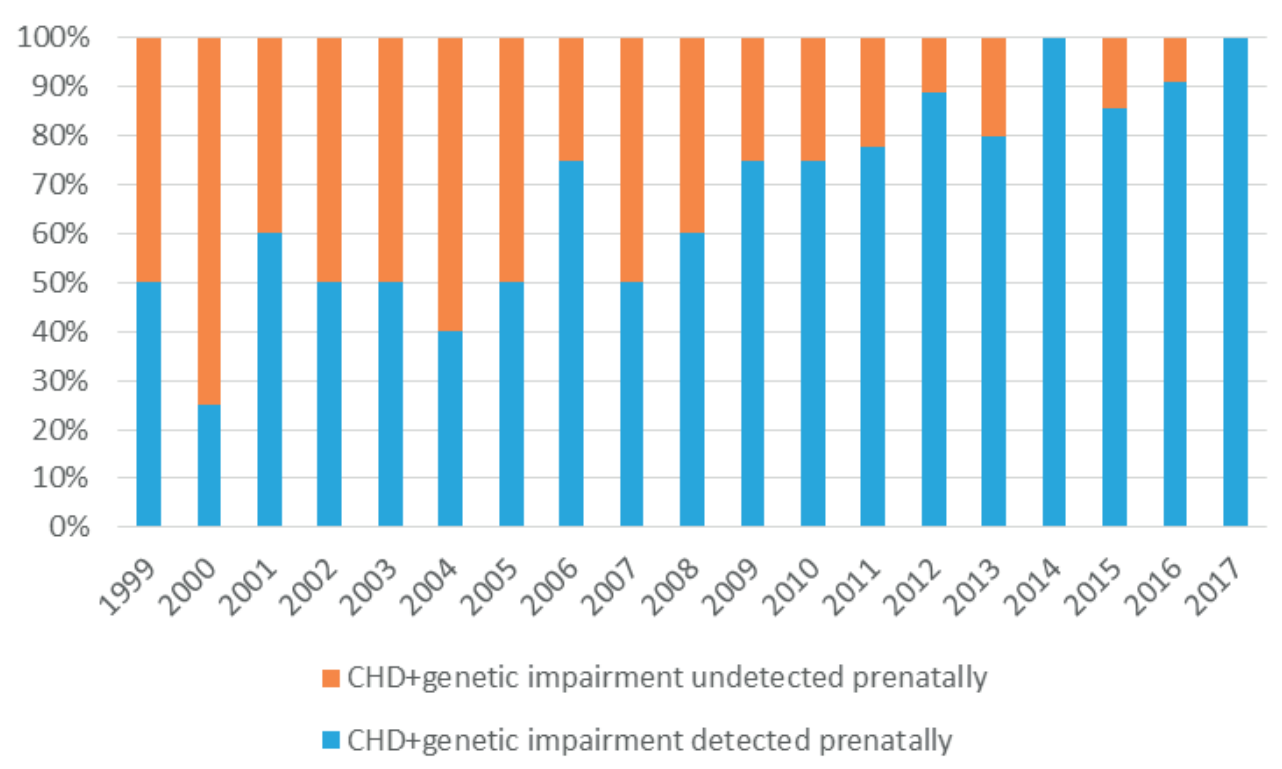

Fig. 2. Proportion of CHDs associated with a genetic diagnosis, prenatally and postnatally $(n=128)$.

- Trisomy 21
- Deletion 22q11
- Trisomy 18
n Trisomy 13
- Monosomy X
- Noonan sy
- Deletion 7q11.23
- Others

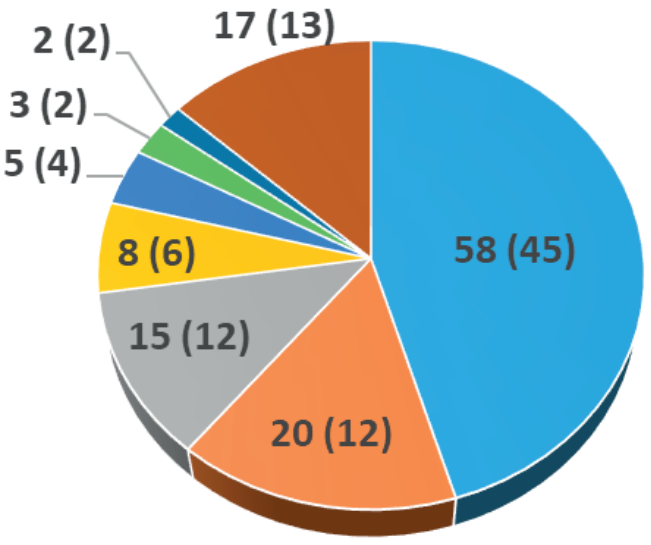

Fig. 3. Representation of genetic syndromes with relation to CHDs, $n(\%),(n=128)$.

The heart defect was observed as an isolated impairment in $78 \%(640 / 819)$ of cases, in association with a genetic impairment in 16\% (128/819), and in association with extra-cardiac malformations without any genetic pathology in $6 \%(51 / 819)$. Table 1 shows the relation between genetic and other extra-cardiac anomalies and individual types of CHDs, Figure 3 shows the genetic syndromes related to CHDs, and Table 2 gives a detailed listing of CHDs in relation to individual genetic abnormalities.

From the total number of chromosomal aberrations and other extra-cardiac anomalies with a normal karyotype, $70 \%(90 / 128)$ and $86 \%(43 / 50)$ respectively were associated with a prenatal diagnosis, and 30\% (38/128) and $14 \%(7 / 51)$ were diagnosed postnatally (Fig. 4A, B). The association between a CHD and genetic pathology was higher prenatally than with postnatal detection [prenatally: $21 \%$ (90/435) vs. postnatally: $10 \%$ (38/384;
$P<0.0001)]$. At the same time, the association of a CHD with another extra-cardiac pathology was prenatally significant [prenatally: $10 \%$ (44/435) vs. postnatally: $2 \%(7 / 384 ; P<0.0001)]$. Among the prenatally detected CHDs, 53\% (229/435) of families decided to terminate the pregnancy. In the group of 229 terminated pregnancies, $58 \%(133 / 229)$ of fetuses were diagnosed with an isolated CHD, 30\% (68/229) had an associated genetic pathology, and $12 \%(28 / 229)$ were associated with another extra-cardiac malformation.

\section{DISCUSSION}

Heart defects are the most frequently observed morphological defects ${ }^{9}$, with a reported incidence in very wide ranges between 6 and 18 cases per 1000 live births ${ }^{11,12}$. These numbers may reach $30 / 1000$ when taking into 
Table 1. Association of CHDs and genetic and morphological impairments from 1999-2017, divided according to the share of chromosomal aberrations.

\begin{tabular}{|c|c|c|c|c|}
\hline CHD & $\mathrm{n}$ & Isolated (\%) & Chromosomal aberrations (\%) & $\begin{array}{l}\text { Extra-cardiac } \\
\text { anomalies (\%) }\end{array}$ \\
\hline Atrioventricular septal defect & 107 & $46(43)$ & $\begin{array}{l}50 \text { (47) } \\
\text { 41x Trisomy 21, 4x Trisomy } 18 \\
\text { 2x Trisomy 13, } \\
\text { 1x Smith-Lemli-Opitz syndrome, } 1 x \text { trans 13/14, } \\
\text { 1x Smith-Magenis syndrome }\end{array}$ & $11(10)$ \\
\hline Interruption of the aortic arch & 10 & $7(70)$ & $\begin{array}{l}3(30) \\
\text { 2x Deletion 22q11, 1x sy cri du chat }\end{array}$ & 0 \\
\hline Common arterial trunk & 17 & $11(65)$ & $\begin{array}{l}5(29) \\
2 x \text { Deletion 22q11, 2x Trisomy 13, } \\
\text { 1x part. deletion 13q }\end{array}$ & $1(6)$ \\
\hline Tetralogy od Fallot & 93 & $65(70)$ & $\begin{array}{l}25(27) \\
8 x \text { Trisomy 21, 8x Deletion 22q11, 2x Noonan sy, } \\
\text { 1x Trisomy 18, 1x } 47 \mathrm{XX}+22 \text {, } \\
1 \mathrm{x} 47 \mathrm{XX}+9,1 \mathrm{x} 46 \mathrm{XY}, 3 \mathrm{x} \text { others }\end{array}$ & $3(3)$ \\
\hline $\begin{array}{l}\text { Pulmonary atresia/ventricular } \\
\text { septal defect }\end{array}$ & 18 & $14(78)$ & $\begin{array}{l}3(17) \\
2 x \text { Deletion 22q11, 1x Trisomy } 13\end{array}$ & $1(5)$ \\
\hline Ventricular septal defect & 119 & $97(82)$ & $\begin{array}{l}18(15) \\
\text { 9x Trisomy 21, 5x Deletion 22q11, 1x Trisomy 18, } \\
\text { 1x Smith Magenis syndrome, } \\
\text { 1x Trisomy 13, 1x other }\end{array}$ & $4(3)$ \\
\hline Tricuspid atresia & 17 & $15(88)$ & $\begin{array}{l}2(12) \\
2 x \text { Trisomy } 18\end{array}$ & 0 \\
\hline Double outlet right ventricle & 43 & $33(77)$ & $\begin{array}{l}5(12) \\
2 x \text { Trisomy 18, 1x Deletion 11q, } \\
1 x \text { Trisomy 13, 1x other }\end{array}$ & $5(11)$ \\
\hline Coarctation of aorta & 78 & $67(86)$ & $\begin{array}{l}7 \text { (9) } \\
\text { 3x Monosomy X, 3x Trisomy 18, 1x Trisomy } 13\end{array}$ & $4(5)$ \\
\hline Hypoplastic left heart syndrome & 63 & $56(89)$ & $\begin{array}{l}5(8) \\
\text { 1x Edwards, 1x Deletion 22q11, } \\
1 \text { x t 13/14, 1x Monosomy X }\end{array}$ & $2(3)$ \\
\hline Single ventricle & 17 & $12(71)$ & $\begin{array}{l}1(6) \\
1 x \text { Trisomy } 18\end{array}$ & $4(23)$ \\
\hline Aortic stenosis & 42 & $38(90)$ & $\begin{array}{l}2(5) \\
\text { 1x Deletion 7q11.23, 1x Noonan syndrome }\end{array}$ & $2(5)$ \\
\hline Pulmonary stenosis & 49 & $46(94)$ & $\begin{array}{l}2(4) \\
\text { 1x monosomy X/inv. 4, 1x Deletion 7q11.23 }\end{array}$ & $1(2)$ \\
\hline Ebstein's anomaly & 16 & $16(100)$ & 0 & 0 \\
\hline $\begin{array}{l}\text { Pulmonary atresia/ intact ven- } \\
\text { tricular septum }\end{array}$ & 17 & $14(82)$ & 0 & $3(18)$ \\
\hline Transposition of great arteries & 78 & $73(94)$ & 0 & $5(6)$ \\
\hline Tumor/rhabdomyoma & 9 & $9(100)$ & 0 & 0 \\
\hline $\begin{array}{l}\text { Total anomaly of pulmonary } \\
\text { venous return }\end{array}$ & 8 & $8(100)$ & 0 & 0 \\
\hline $\begin{array}{l}\text { Corrected transposition of great } \\
\text { arteries }\end{array}$ & 7 & $5(71)$ & 0 & $2(29)$ \\
\hline Dextrocardia & 6 & $6(100)$ & 0 & 0 \\
\hline Mitral atresia & 4 & $2(50)$ & 0 & $2(50)$ \\
\hline Ectopia cordis & 1 & 0 & 0 & $1(100)$ \\
\hline Total & 819 & $640(78)$ & $128(16)$ & $51(6)$ \\
\hline
\end{tabular}




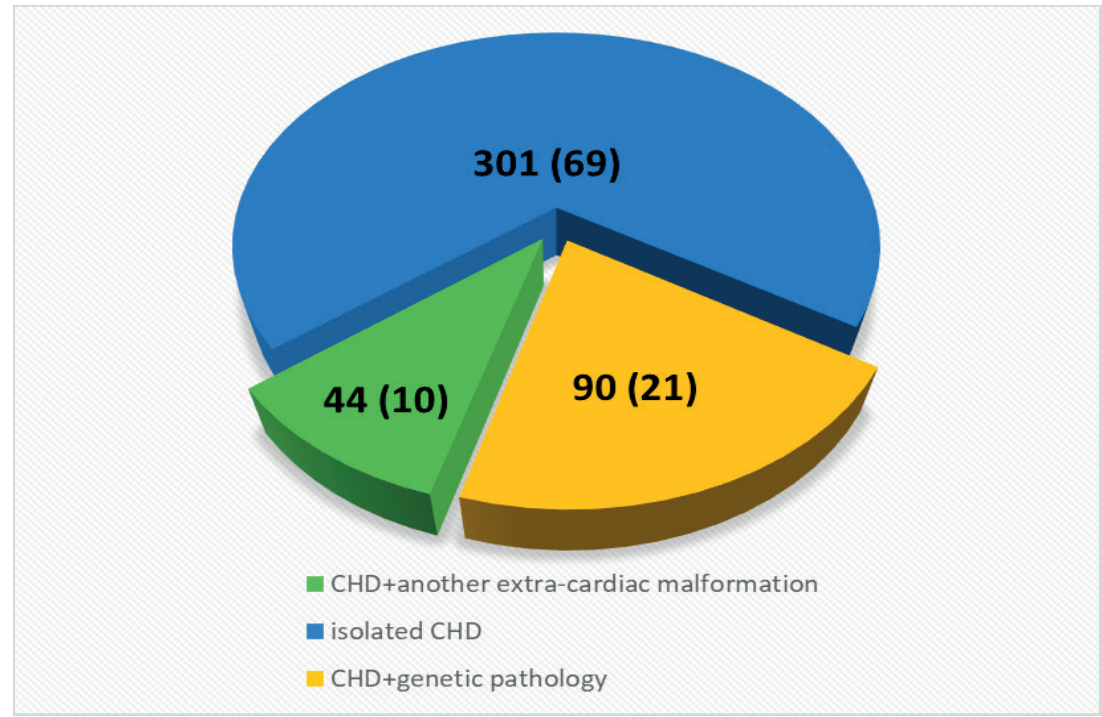

Fig. 4. (A) Prenatally diagnosed CHDs, n (\%).

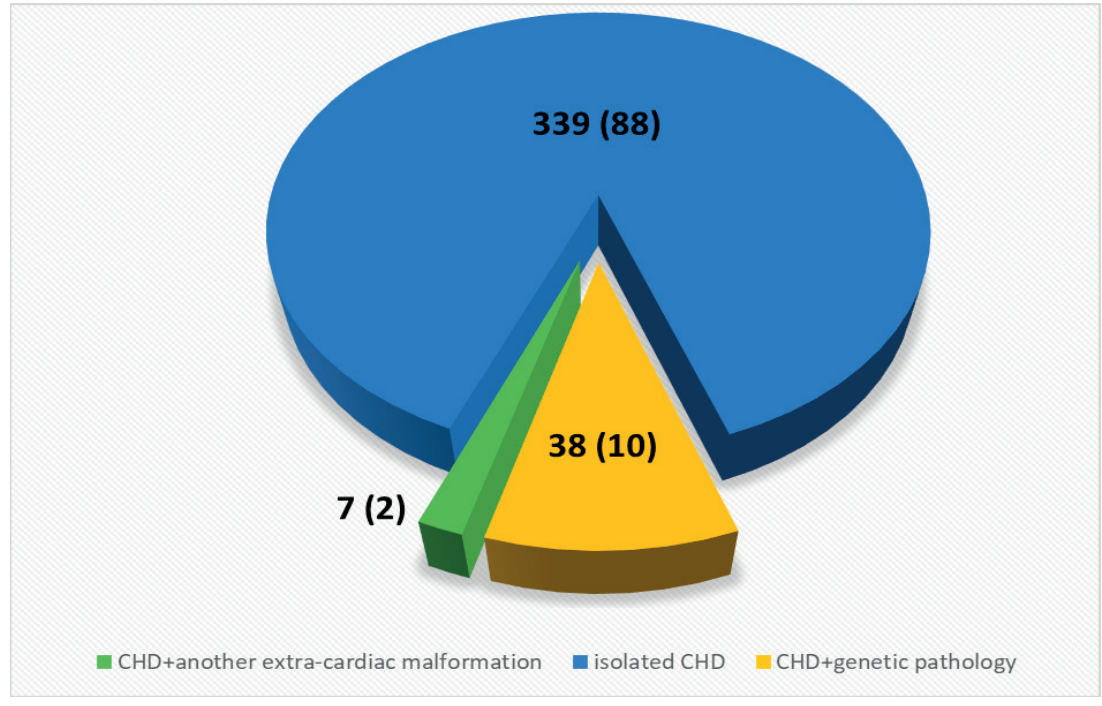

Fig. 4. (B) Postnatally diagnosed CHDs, $n(\%)$.

Table 2. Genetic pathologies and types of observed CHDs.

\begin{tabular}{lrl}
\hline Trisomy 21 & 58 & 41x AVSD, 9x VSD, 8x TOF, \\
Deletion 22q11 & 20 & 8x TOF, 5x VSD, 2x CAT, 2x PAVSD, 2x IAA, 1x HLH \\
Trisomy 18 & 15 & 4x AVSD, 2x DORV, 2x TA, 2x DORV, 1x TOF, 1x SV, 1x HLH, 1x CoA, 1x VSD \\
Trisomy 13 & 8 & 2x AVSD, 2x CAT, 1x PAVSD, 1x VSD, 1x DORV, 1x COA \\
Monosomy X & 5 & 3x CoA, 1x HLH, 1x PS \\
Noonan syndrome & 3 & 2x TOF, 1x AS \\
Deletion 7q11.23 & 2 & 1x AS, 1x PS \\
others & 17 & 6x TOF, 3x AVSD, 2x VSD, 2x DORV, 1x CAT, 1x IAA, 1x HLH, 1x PS \\
\hline Total & 128 & \\
\hline
\end{tabular}

(abbreviations see Fig. 1)

consideration bicuspid aortic valves, and 75 cases per 1000 live births when including all insignificant forms of CHDs, including minor septal defects ${ }^{13}$. The development of a heart defect is most probably associated with a combination of genetic and non-genetic factors ${ }^{14}$. Despite advancements in medical genetics, the cause of a large proportion of these defects remains unknown, and from the clinical point of view, it is necessary to take into account environmental factors and accept the validity of the multifactorial hypothesis ${ }^{15}$. The main findings of our study are as follows: i) prenatal diagnostics of extra-cardiac pathologies has improved with the increasing effectiveness 
of prenatal diagnostics of CHDs; ii) in most cases, CHDs are observed as an isolated finding; iii) the most frequent CHD associated with a genetic abnormality is atrioventricular septal defect, and the most frequently observed syndrome associated with CHDs is trisomy 21; and iv) the diagnostics of a CHD associated with a genetic or other extra-cardiac pathology is significantly associated with the prenatal period, and the pathological diagnosis contributes to the parents' decision-making concerning pregnancy termination.

Fetal echocardiography is a very precise technique for detection of cardiac malformations, providing excellent results when performed by an experienced physician ${ }^{16,17}$. The highest yield and possibility for assessing the heart anatomy remains between the $18^{\text {th }}$ and $22^{\text {nd }}$ weeks of pregnancy ${ }^{18}$, and we still prefer this period, despite advances in ultrasound techniques. It is also possible to offer early fetal diagnostics in cases of pregnancies associated with risk factors ${ }^{19-21}$. The success rate of prenatal diagnostics of CHDs has generally increased ${ }^{22}$, with some variation among countries ${ }^{23}$. In the Czech Republic, prenatal detection of CHDs is high, as in much of Europe. In the Czech Republic the rate increased from $0.6 \%$ in 1986 to $36.5 \%$ in 2009 (ref. ${ }^{24}$ ); from 2002 and 2009, it varied between 70 and $83 \%$ (ref. ${ }^{25}$ ), and up to $95 \%$ of cases of hypoplastic left heart syndrome were detected in recent years ${ }^{26}$. In this study, half of significant CHDs were first diagnosed prenatally in 2005, but this yield subsequently increased to the current level of $80 \%$, and CHDs altering the shape of the four chambers of the heart are presently detected in $100 \%$ of cases.

At the same time, great advancements have been observed in medical genetics ${ }^{27}$. Karyotype testing continues to play an important role, and we use it in pediatric cardiology in patients with a suspicion of a clear chromosomal syndrome (Trisomies 13, 18, 21, monosomy X). The FISH (fluorescent in situ hybridization) technique is used specifically in patients with CHDs associated with a suspicion of microdeletion syndromes (DiGeorge, Williams-Beuren, Smith-Magenis). Another technique that has become more and more popular is the comparative genomic hybridization $(\mathrm{CGH})$ array $^{28}$, a molecular cytogenetic technique for mapping submicroscopic changes in the whole genome. It is the first-choice technique in diagnostics of developmental disorders and autism; in pediatric cardiology, this technique is used in CHDs combined with other defects, atypical facial features, or dermatoglyphic pathologies.

Classical molecular genetics is aimed at one specific gene or detection of a certain mutation. Another possibility is multiplex ligation-dependent probe amplification, with the option to combine various probes to detect more complex changes (e.g., Prader-Willi syndrome). Recently, the possibility of whole-genome or whole-exome scanning (next-generation sequencing; NGS) has been developed. The so-called panel assessment (sequencing of many genes at the same time for mutations that may be responsible for the given clinical picture or disease) may be used to diagnose cardiomyopathies or in arrhythmology.
In fetal medicine, we perform karyotype testing or a targeted FISH test following amniocentesis or chorionic villi sampling; in cases of combined defects or other ultrasound pathologies, we use array CGH (with the perspective that the array $\mathrm{CGH}$ testing will become the technique of choice during each prenatal invasive assessment). Sequencing is not yet being used in the clinical practice of fetal medicine. Preimplantation screening is gaining importance in reproductive medicine, performed from embryonic cells or trophoblasts (array CGH, NGS) for chromosomal changes, together with preimplantation diagnostics and testing aimed at the given disorder or mutation.

Of the original $5-10 \%$ share of genetic abnormalities associated with the etiology of CHDs, approximately one third have been clarified. Most of the known causes of CHDs are de novo or inherited genetic abnormalities (chromosomal syndrome, de novo copy number variants, de novo gene mutation, inherited gene mutation). Despite improvements in detection and interpretation techniques, complications of phenotype heterogeneity and incomplete penetration are possible ${ }^{29}$. Unknown etiology remains in two thirds of cases of CHDs. Among our patients, $22 \%$ of fetuses and children had a CHD associated with another impairment (16\% chromosomal aberrations, $6 \%$ extra-cardiac pathologies with a normal karyotype), corresponding to the results of other studies ${ }^{30}$. Nevertheless, it is also possible to find patient files with a higher share of extracardiac pathologies ${ }^{31}$. The current results were obtained over a relatively long period of time, and the genetic cause was diagnosed in $22 \%$ of CHDs in 2017, of which $8 \%$ of fetuses had a CHD with another morphological pathology.

Significant and critical CHDs were observed in the monitored population, with an incidence of 3.7 cases per 1000 live births, similar to other studies ${ }^{32}$. The most frequently observed significant CHD was ventricular septal defect. The highest frequency of genetic abnormalities was associated with atrioventricular septal defects (47\%), with a dominant Down syndrome found in 38\% of cases, as also presented in the literature ${ }^{33}$. Other conditions reaching over $25 \%$ of the genetic share in CHD etiology were common arterial truncus, interruption of the aortic arch, and tetralogy of Fallot. Trisomies 21, 18, and 13 and $22 \mathrm{q} 11$ deletion (DiGeorge syndrome) were responsible for $80 \%$ of all genetic abnormalities. Turner syndrome, which is the most common female chromosomal aberration, was most commonly associated with coarctation of aorta. A CHD is observed on average in $50 \%$ of people with Down syndrome $^{34}$; in our work, it was the most frequently observed genetic pathology associated with a CHD and, with the exception of the above mentioned atrioventricular septal defects, was most often associated with the tetralogy of Fallot and ventricular septal defects. The second most frequent aberration was DiGeorge syndrome, most frequently seen with tetralogy of Fallot ${ }^{35}$. It is interesting to note the identical incidence of trisomy 21 and $22 \mathrm{q} 11$ deletion in our study. Trisomy 18, as the third most frequent chromosomal pathology, was also observed with a predominance of atrioventricular septal defects. During the monitored period, no genetic pathology was observed 
in association with Ebstein's anomaly, pulmonary atresia with an intact ventricular septum, transposition of great arteries, total anomalous pulmonary return, tumors of the rhabdomyoma type, corrected transposition of great arteries, isolated dextrocardia, and rare ectopia cordis.

The diagnostics of CHDs, including their association with genetic and other concomitant anomalies, is currently significantly linked to prenatal diagnostics, and most of these significant pathologies are identified prenatally. This increased effectiveness has been enabled by significant development of cooperation between ultrasound diagnostics and genetics. The cooperation is bidirectional: a gynecologist or pediatric cardiologist indicates further testing of the fetus upon discovery of a CHD, or the geneticist indicates further assessment of the fetus when significant risks are identified in the family history or during ongoing pregnancy.

Some parents decide to terminate the pregnancy when a defect is detected. The number of terminated pregnancies upon diagnosis of a fetal CHD significantly varies among registries, from 0 to $50 \%$. The Czech Republic is a country with the highest number of terminations. Parental decision-making is influenced by the significance of the $\mathrm{CHD}$, age, and associated anomalies ${ }^{36}$. Early fetal diagnostics of significant defects results in termination rates of over $70 \%$. During the monitored period in the current work, $53 \%$ of families chose to terminate the pregnancy when a CHD was diagnosed prenatally. Of the terminated pregnancies, $30 \%$ had a chromosomal aberration and $12 \%$ another extra-cardiac impairment.

One of the advantages of our study is the longterm monitoring of development of prenatal diagnostics of CHDs in the region, precise determination of its effectiveness, and knowledge of all significant cardiac pathologies, including extra-cardiac impairments. A disadvantage of the study is the postnatal limitation to significant heart defects only; however, we consider this sufficient for the purpose and sense of prenatal care.

\section{CONSLUSION}

In conclusion, our data indicate that a heart defect usually occurs as an isolated impairment. Genetic and other extra-cardiac anomalies are associated with approximately one third of cardiac diagnoses and are significantly linked to prenatal diagnostics. Associated anomalies contribute to the decision-making of parents regarding termination of pregnancy. Careful further assessment of the pathological pregnancy is critical, and appropriate counseling must be provided for the affected family.

Acknowledgement: This study was supported by the grant MZ VES 2017 (Reg. No. NV17-29111A).

Author contributions: JP: data collection, manuscript writing, responsible for pregnant women's diagnostics and treatment; EK: data interpretation, final approval; TG, SP: pregnant women's diagnostics and treatment; MP: genetic consultation, data interpretation; SK, ES, RK, RC: data interpretation.
Conflict of interest statement: The authors state that there are no conflicts of interest regarding the publication of this article.

\section{REFERENCES}

1. van der Linde $D$, Konings EE, Slager MA, Witsenburg M, Helbing WA, Takkenberg JJ, Roos-Hesselink JW. Birth prevalence of congenital heart disease worldwide. J Am Coll Cardiol 2011;58:2241-7.

2. Sípek A, Gregor V, Sípek A Jr, Hudáková J, Horácek J, Klaschka J, Skibová J, Langhammer $\mathrm{P}$, Petrzílková L, Klímová B, Perinová B, Wiesnerová J. Incidence of congenital heart defects in the Czech Republic-current data. Ceska Gynekol 2010;75:221-42.

3. Wessels MW, Willems PJ. Genetic factors in non-syndromic congenital heart malformation. Clin Genet 2010;78:103-23.

4. Shi H, O'Reilly VC, Moreau JL, Bewes TR, Yam MX, Chapman BE, Grieve SM, Stocker R, Graham RM, Chapman G, Sparrow DB, Dunwoodie SL. Gestational stress induces the unfolded protein response, resulting in heart defects. Development 2016;143:2561-72.

5. Blue GM, Kirk EP, Sholler GF, Harvey RP, Winlaw DS. Congenital heart disease: current knowledge about causes and inheritance. The Medical Journal of Australia 2012;197:155-9.

6. Raymond FL, Simpson JM, Sharland GK, Ogilvie CM. Fetal echocardiography as a predictor of chromosomal abnormality. The Lancet 1997;350:930.

7. Pierpont ME, Basson CT, Benson DW, Gelb BD, Giglia TM, Goldmuntz E, McGee G, Sable CA, Srivastava D, Webb CL. Genetic basis for congenital heart defects: current knowledge. Circulation 2007;115:301538.

8. Richards AA, Santos LJ, Nichols HA, Crider BP, Elder FF, hauser NS, Zinn AR, Garg V. Cryptic chromosomal abnormalities identified in children with congenital heart disease. Pediatr Res 2008;64:358-63.

9. Fahed AC, Gelb BD, Seidman JG, Seidman CE. Genetics of Congenital Heart Disease. Circulation research 2013;112:707-20.

10. Zhu RY, Gui YH, Li LC, Chen RY, Sun L, Chang C. Fetal echocardiography in diagnosing congenital heart disease prenatally: a multicenter clinical study. Chinese journal of pediatrics 2006;44:764-9.

11. Baspinar O, Karaaslan S, Oran B, Baysal T, Elmaci AM, Yorulmaz A. Prevalence and distribution of children with congenital heart diseases in the central Anatolian region, Turkey. Turk J Pediatr 2006;48:23743.

12. Bolisetty S, Daftary A, Ewald D, Knight B, Wheaton G. Congenital heart defects in Central Australia. Med J Aust 2004;180:614-7.

13. Hoffman Jl, Kaplan S. The incidence of congenital heart disease. J Am Coll Cardiol 2002;39:1890-900.

14. Riehle-Colarusso TJ, Patel SS. Maternal Nongenetic Risk Factors for Congenital Heart Defects. In: Congenital Heart Disease. Karger Publishers; 2015. p. 57-69.

15. Nora JJ. Multifactorial inheritance hypothesis for the etiology of congenital heart diseases. Circulation 1968;38:604-17.

16. Yu ZB, Han SP, Guo XR. Meta-analysis of the value of fetal echocardiography for the prenatal diagnosis of congenital heart disease. Chin J Evid Based Pediatr 2009;4:330-9.

17. Co-Vu J, Ivsic T. Fetal Echocardiography to Diagnose Fetal Heart Disease. Neoreviews 2012;13:e590-e604.

18. Campbell S, Allan L, Benacerraf B, Copel JA, Carvalho JS, Chaoui R (2001). Isolated major congenital heart disease. Ultrasound Obstet Gynecol 2001;17:370-9.

19. ACOG Committee on Practice Bulletins. AGOG practice bulletin No 58. Ultrasonography in pregnancy. Obstet Gynecol 2004;58:1449-58.

20. Bellotti M, Fesslova V, De Gasperi C, Rognoni G, Bee V, Zucca I, Lombardi CM. Reliability of the first-trimester cardiac scan by ultrasound-trained obstetricians with high-frequency transabdominal probes in fetuses with increased nuchal translucency. Ultrasound Obstet Gynecol 2010;36:272-8.

21. Comas GC, Galindo A, Martinez JM, Carrera JM, Gutiérrez-Larraya F, de la Fuente P, Puerto B, Borrell A. Early prenatal diagnosis of major cardiac anomalies in a high risk population. Prenat diagn 2002;22:586-93.

22. Khoshnood B, De Vigan C, Vodovar V, Goujard J, Lhomme A, Bonnet $D$, Goffinetet $F$. Trends in prenatal diagnosis, pregnancy termination, and perinatal mortality of newborns with congenital 
heart disease in France, 1983-2000: a population-based evaluation. Pediatrics 2005;115:95-101.

23. Garne E, Stoll C, Clementi M. Evaluation of prenatal diagnosis of congenital heart diseases by ultrasound: experience from 20 European registries. Ultrasound Obstet Gynecol 2001;17:386-91.

24. Jičínská H. Prenatální kardiologie v České republice. Čes-slov Pediat 2010;65:623-5.

25. Tomek V, Marek J, Jičínská $\mathrm{H}$, Škovránek J. Fetal cardiology in the Czech Republic: Current management of prenatally diagnosed congenital heart disease and arrhythmias. Physiol. Res 2009;58,Suppl. 2:159-66.

26. Marek J, Tomek V, Škovránek J, Povýšilova V, Šamánek M. Prenatal ultrasound screening of congenital heart disease in an unselected national population: a 21-year experience. Heart 2011;97:124-30.

27. Akhirome E, Walton NA, Nogee JM, Jay PY. The Complex Genetic Basis of Congenital Heart Defects. Circ J 2017;81:629-34.

28. Miller DT, Adam MP, Aradhya S, Biesecker LG, Brothman AR, Carter NP, Church DM, Crolla JA, Eichler EE, Epstei ChJ, Faucett WA, Feuk L, Friedman JM, Hamosh A, Jackson L, Kaminsky EB, Kok K, Krantz ID, Ledbetter DH. Consensus statement: chromosomal microarray is a first-tier clinical diagnostic test for individuals with developmental disabilities or congenital anomalies. Am J Hum Genet 2010;86:74964

29. Edwards JJ, Gelb BD. Genetics of congenital heart disease. Curr opin cardiol 2016:31:235-41.

30. Dadvand P, Rankin J, Shirley MD, Rushton S, Pless-Mulloli T.
Descriptive epidemiology of congenital heart disease in Northern England. Paediatr Perinat Ep 2009;23:58-65.

31. Song MS, Hu A, Dyhamenahali U, Chitayat D, Winsor EJT, Ryan G, Smallhorn H, Barett J, Yoo SJ, Hornberger LK. Extracardiac lesions and chromosomal abnormalities associated with major fetal heart defects: comparison of intrauterine, postnatal and postmortem diagnoses. Ultrasound Obstet Gynecol 2009;33:552-9.

32. Tegnader $\mathrm{E}$, Williams $\mathrm{O}$, Johansen SJ, Blaas HGK and Eik-Nes SH. Prenatal detection of heart defects in a non-selectes population of 30149 fetuses-detection rates and outcome. Ultrasound Obstet Gynecol 2006;27:252-65.

33. Tumanyan MR, Filaretova OV, Chechneva VV, Gulasaryan RS, Butrim IV, Bockeria LA. Repair of complete atrioventricular septal defect in infants with Down syndrome: outcomes and long-term results. Pediatr cardiol 2015;36:71-5.

34. Bergström S, Carr H, Petersson G, Stephansson O, Bonamy AK E, Dahlström A, Halforsen CP, Johansson S. Trends in congenital heart defects in infants with down syndrome. Pediatrics 2016;e20160123.

35. Goldmuntz E, Clark BJ, Mitchell LE, Jawad AF, Cuneo BF, Reed L, McDonald-McGinn D, Chien P, Feuer J, Zackai EH, Emanuel BS, Driscoll DA. Frequency of 22q11 deletions in patients with conotruncal defects. J Am Coll Cardiol 1998;32:492-8.

36. Chenni N, Lacroze V, Pouet C, Fraisse A, Kreitmann B, Gamerre M, Boubli L, D'ercole $C$. Fetal heart disease and interruption of pregnan$c y$ : factors influencing the parental decision-making process. Prenat diagn 2012;32:168-72. 